\title{
Black Sea vertical circulation and extremes of the hydrochemical and hydrooptical parameters
}

\author{
Sergey N. BULGAKOV a,b ${ }^{\text {, Vladimir M. KUSHNIR }}{ }^{\text {a }}$, Alejandro MARTINEZ Z. ${ }^{\text {b }}$ \\ ${ }^{a}$ Marine Hydrophysical Institute, 2 Kapitanskaya St., Sevastopol, 335000, Ukraine; ocean@ mhi2.sebastopol.ua \\ ${ }^{\mathrm{b}}$ Instituto de Astronomia y Meteorologia, Universidad de Guadalajara, 2602 Av. Vallarta, C.P. 44130, Jalisco, Mexico; \\ sbulgako@udgserv.cencar.udg.mx
}

(Received 15 January 1998, revised 30 November 1998, accepted 8 December 1998)

\begin{abstract}
A statistical evaluation of vertical current velocity profiles $w(z)$ has been undertaken using data provided by current meter profilers. The calculation of profiles $w(z)$ involves the estimation of the standard deviation of vertical current at each depth level, and the standard deviation of the statistical variability of that estimate. Profiles $w(z)$ have been computed for the northwestern Black Sea, using current meter and CTD data from three surveys carried out during 1992-1994. The calculations show $w(z)$ to have a two-layered structure, with zero values occurring in the main pycnocline. Such vertical current structures are consistent with a hydrodynamic model, whereby the current field is induced by buoyancy fluxes through the lateral basin boundaries. Existence of zero vertical current velocities at the pycnoclines yields the key to understanding the mechanisms responsible for the oxic-anoxic interface, and of the zones with steep vertical gradients in hydrochemical and hydrooptical characteristics. (C) Elsevier, Paris / Ifremer / CNRS / IRD
\end{abstract}

\section{Black Sea / vertical circulation / hydrochemistry / hydrooptics}

Résumé - Circulation verticale dans la mer Noire et valeurs extrêmes des variables chimiques et optiques. Une étude statistique des courants verticaux dans le nord-ouest de la mer Noire a été effectuée à partir de données (courantométrie et sonde CTD) acquises en 1992-1994 au cours de trois campagnes. Les écarts types ont été estimés à chaque profondeur pour le courant vertical et sa variabilité statistique. Les calculs révèlent une structure à deux couches avec des courants verticaux qui s'annulent dans la pycnocline principale. Ce résultat est en accord avec le modèle dynamique dans lequel le champ de courant est induit par les flux de densité à travers les frontières latérales du bassin. Les vitesses verticales nulles dans les pycnoclines expliquent l'apparition d'une interface oxique-anoxique, ainsi que les forts gradients verticaux dans les caractéristiques chimiques et optiques. (C) Elsevier, Paris / Ifremer / CNRS / IRD

mer Noire / circulation verticale / chimie marine / optique marine

\section{INTRODUCTION}

The ventilation of the Black Sea and general structure of the vertical sea water circulation is a serious question. On the one hand, there is the problem that it is impossible to measure the vertical current velocity. On the other hand, there is the problem of describing the vertical velocity field in three-dimensional hydrodynamic numerical calculations. Investigations of this problem [29, 34, 36, 38] have demonstrated that the quality of vertical velocity component simulations is still unsatisfactory; the results of numer- ical experiments depend strongly upon both the numerical schemes employed, and initial hydrological data.

Nevertheless, several models of vertical circulation within the Black Sea have been developed with differing levels of complexity $[6,15,16,27,30,32,39]$. In many of the references, it is noted that there is a general upwelling of deep waters in the central Black Sea, as well as a compensating downwelling in the coastal region. It is supposed [3], that a vertical distribution of hydrological characteristics, with the dome-shaped pycnocline directed upwards from the coastal region to the central 
basin, may serve as an illustration of the kind of vertical circulation cell which exists in the Black Sea. According to the references cited above, vertical current velocities are in the range of $10^{-4}-10^{-8} \mathrm{~m} \cdot \mathrm{s}^{-1}$, values similar to those encountered in larger ocean areas.

It is common knowledge that the Black Sea is an example of a nearly enclosed sea water basin, with intensive buoyancy flux forcing through open lateral boundaries (due to river run-off and salt water inflow from the Mediterranean Sea through the Bosphorus strait). To investigate this forcing, a theoretical study $[7,8]$ was carried out using 2-dimensional analytical and numerical hydrodynamic models. It was shown that the above-mentioned driving force could play an important role in large-scale circulation and stratification within the Black Sea. The buoyancy flux-induced circulation at the basin surface was shown to be of a cyclonic nature, with jet-stream characteristics, and a boundary layer structure similar to that of the Black Sea Rim current. Moreover, it was dem- onstrated that intrusion of tresh waters at the surface, and salt waters at the mid depths, generates a 3-layered horizontal circulation in the vertical direction.

In order to verify the theoretical results, a set of laboratory experiments using buoyancy flux forcing in a rotating tank was conducted at the Woods Hole Oceanographic Institution [9, 10]. The laboratory parameters were chosen so as to induce dynamic processes similar to those in the Black Sea, based on an equality between the dimensionless Rossby and external forcing numbers. The stable and steady regimes of the circulation were studied, as a result of which it was apparent that lab experiments were in good agreement with theory.

The vertical motion of sea water under conditions of buoyancy flux forcing is characterized by the following patterns. Two cells of vertical circulation having opposite rotation are formed in the upper and lower layers, with zero velocities occurring at the main pycnocline

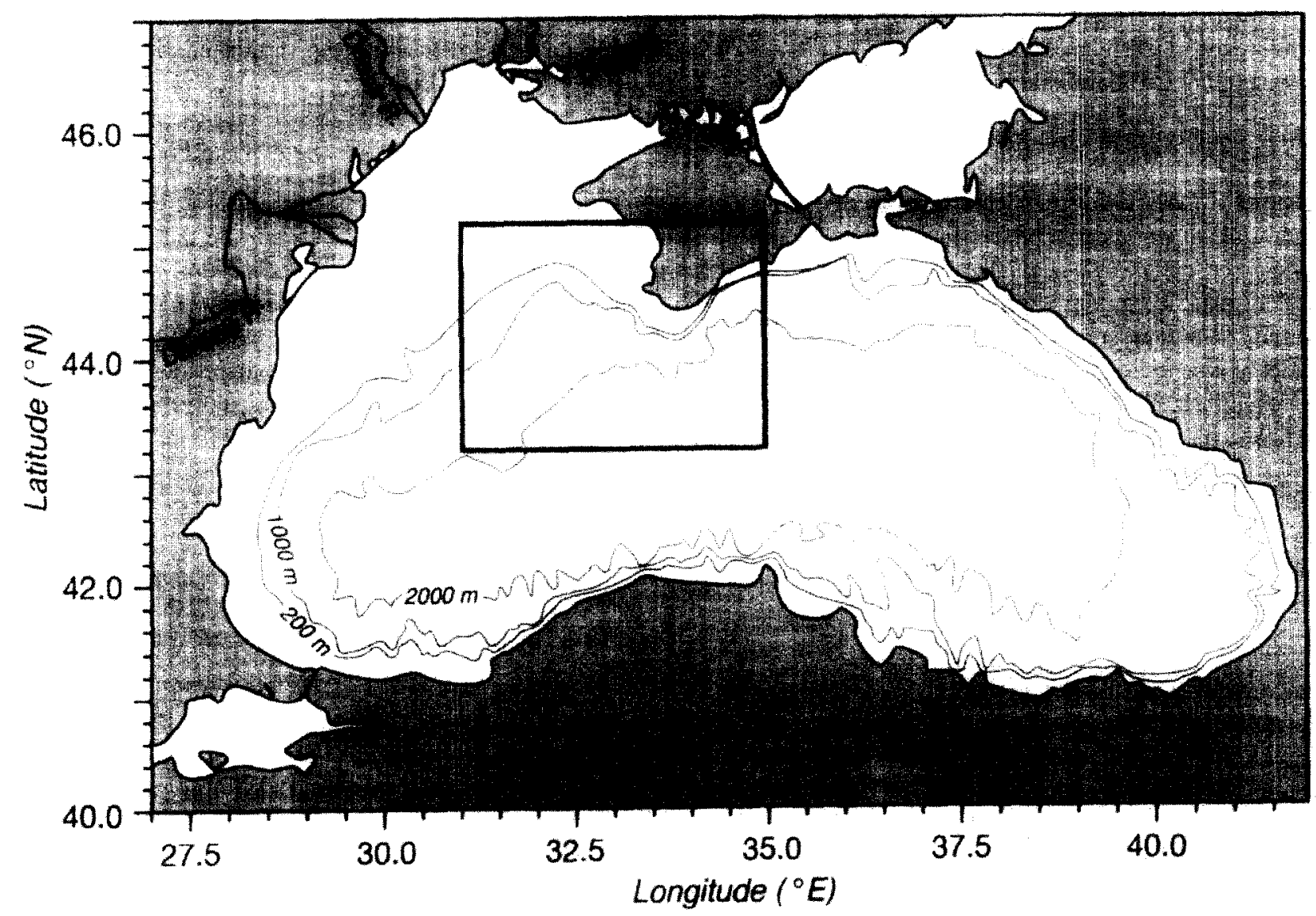

Figure 1. Map of the Black Sea. The square shows the experimental area. 
zone. An upwelling of near-surface water takes place in the coastal regions, and an intrusion of dense waters through the open lateral boundaries leads to a downwelling at deeper horizons. An opposite situation occurs in the open sea basin. The structure of $w(z)$ is characterized there by downwelling of sea waters at the surface layer, and by upwelling of the deeper layers below the main pycnocline depths. Thus, the vertical motion of sea water results in a two-layered structure, with zero velocities at the mid depths of both the boundary and open sea basin regions. Opposing vertical flows in the surface and deeper layers, with negligible vertical velocities at the mid depths could, in turn, supply an explanation for the existing extremes of both hydrochemical and hydrooptical parameters, known from observations in the Black Sea $[2,4,5,14,17,28,31,35,37]$.

In this paper vertical velocities in the northern Black Sea are evaluated during 1992-1994, using both current meter and CTD observations. A broad agreement is shown between these most recent measurements, and the model of vertical circulation cited above.

\section{OBSERVATIONS}

The characteristics of the $w(z)$ structure were calculated from data derived from three surveys carried out by the Marine Hydrophysical Institute (Sevastopol, Ukraine) in August 1992 (R.V. Y. Gakkel), in October-November 1993 (R.V. Trepang, Cruise 15) and in December 1994 (R.V. Prof. Kolesnikov, Cruise 32) using an acoustic current meter profiler OLT [21]. The main purposes of these surveys were to investigate the vertical structure of the current field in the Black Sea, and to obtain synchronous data on spatial current structures, and the distributions of hydrological elements $[11,12,22]$. Profiling of the hydrophysical parameters was undertaken using an OLT profiler, and ranged from the surface to depths of 500$1000 \mathrm{~m}$, with a horizontal spacing of $10-20 \mathrm{~km}$. Locations of the deep-water stations ( $>500 \mathrm{~m}$ ) for these three surveys, and distributions of the dynamic heights at the surface of the experimental area are shown in figures 1 and 2 .

Besides carrying out the standard hydrological and current meter measurements, hydrooptical and hydrochemical observations were also taken in cruise 32 of the R.V. Prof. Kolesnikov. One of the main goals of this series of studies was to determine possible relations between the kinematic, hydrological, hydrooptical and hydrochemical parameter distributions.

The hydrooptical data were sampled using a continuous vertical profiling system OGH (optico-hydrological probe in Russian abbreviation) constructed at the Marine Hydrophysical Institute (Sevastopol, Ukraine). OGH-type hydrooptic and CTD prohe allowed the collection of continuous profiles of salinity, temperature, pressure, and sea water transparency $(\varepsilon)$ for a variety of spectral ranges.

A vertical cross-section indicating sea water density $\left(\sigma_{t}\right)$ and transparency $(\varepsilon)$ along $33^{\circ} 15^{\prime} \mathrm{E}$, from data sampled during December 1994, are shown respectively in figures 3 and 4 . The sharp extremes of this hydrooptical parameter are visible at depths of 100-200 m (figure 4), where it appears that this hydronptical characteristic of the Black Sea water (the so-called deep turbid layer) is being observed at the permanent pycnocline. This feature can usually be observed in the open basin part of the Black Sea, and it is not normally present in the coastal regions [28].

The close correlation of the deep turbid layer position and the lower boundary of the permanent pycnocline (15.9$16.2 \sigma_{\mathrm{t}}$ ) can be observed in figures 3,4 . From the processing of data from about 40 hydrological and hydrooptical stations, it was established that the maximum in $\varepsilon$ is located at the $15.9-16.2 \sigma_{t}$-surfaces with a mean value of 16.02 , and standard deviation 0.01 .

There are different views on the cause of the deep turbid layer [28]. One of these hypotheses is that it has its origin in biological processes associated with mid-depth bacteria. Another attributes its formation to hydrochemical processes in the main pycnocline, as a result of the mixing of waters with different chemical characteristics. Finally, a third point of view explains deep turbid layer formation in terms of the intrusion of muddier waters from the Marmara Sea.

It is also possible to suppose that both the structure and depth of the deep turbid layer (as well as that of the permanent pycnocline) are determined hy dynamic processes. Using the above-mentioned theoretical scheme for vertical circulation in the Black Sea, it is possible to imagine that it is the vertical transport across isopycnal surfaces that acts as a controlling mechanism. So, the vertical flow convergence at the mid-depth of the open sea basin provides a mechanism for the accumulation of sediment, and for the formation of the hydrooptical extremes there. By contrast, the vertical flow divergence at the 


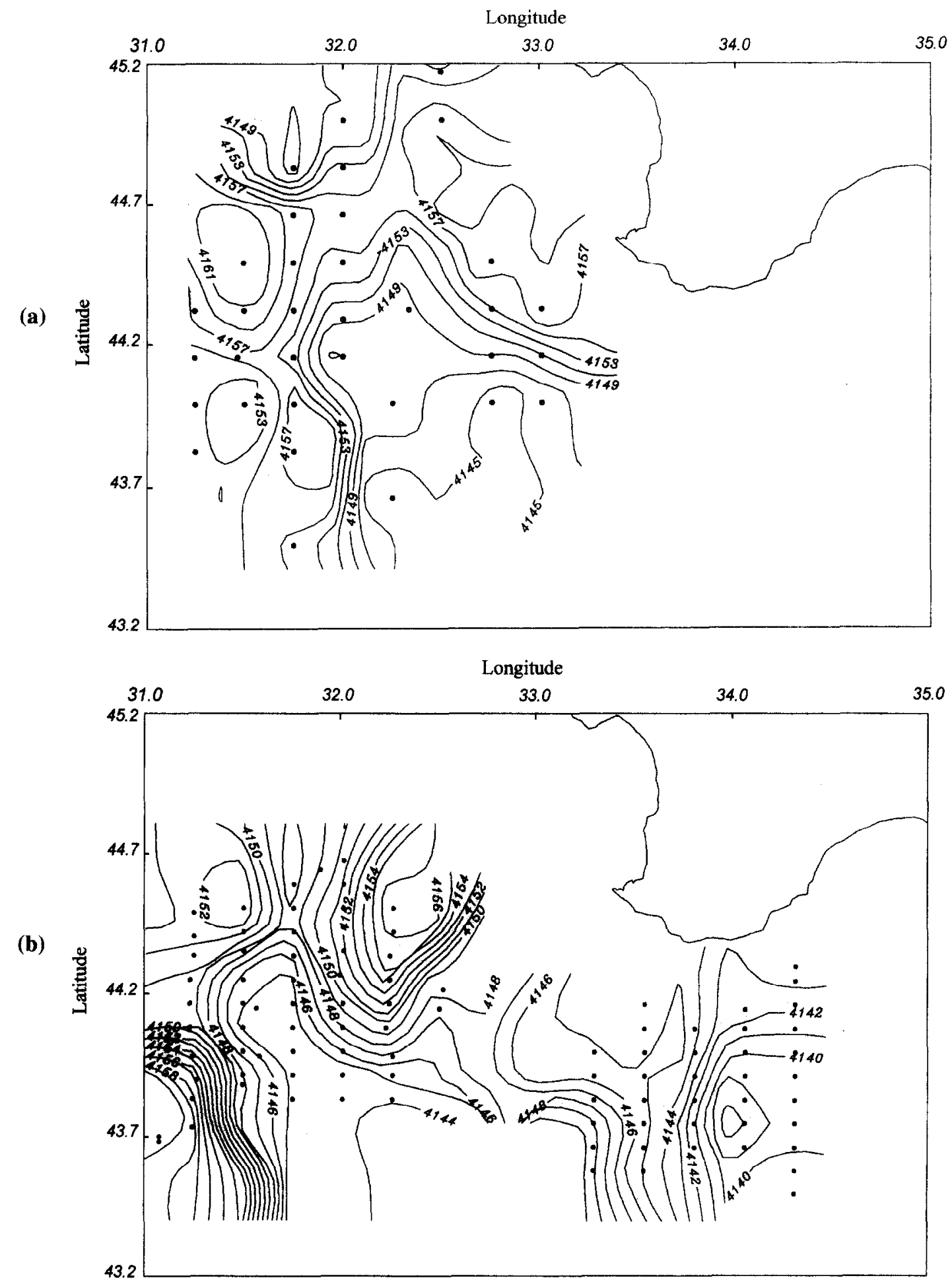

Figure 2a, b, c. Dynamic topography at the surface of experimental area in relation to $500 \mathrm{dbar}$. Locations of deep-water stations ( $>500 \mathrm{~m}$ ) are shown as dots.

a - August 1992 (R.V. Y. Gakkel). b - October-November 1993 (R.V. Trepang, Cruise 15). 


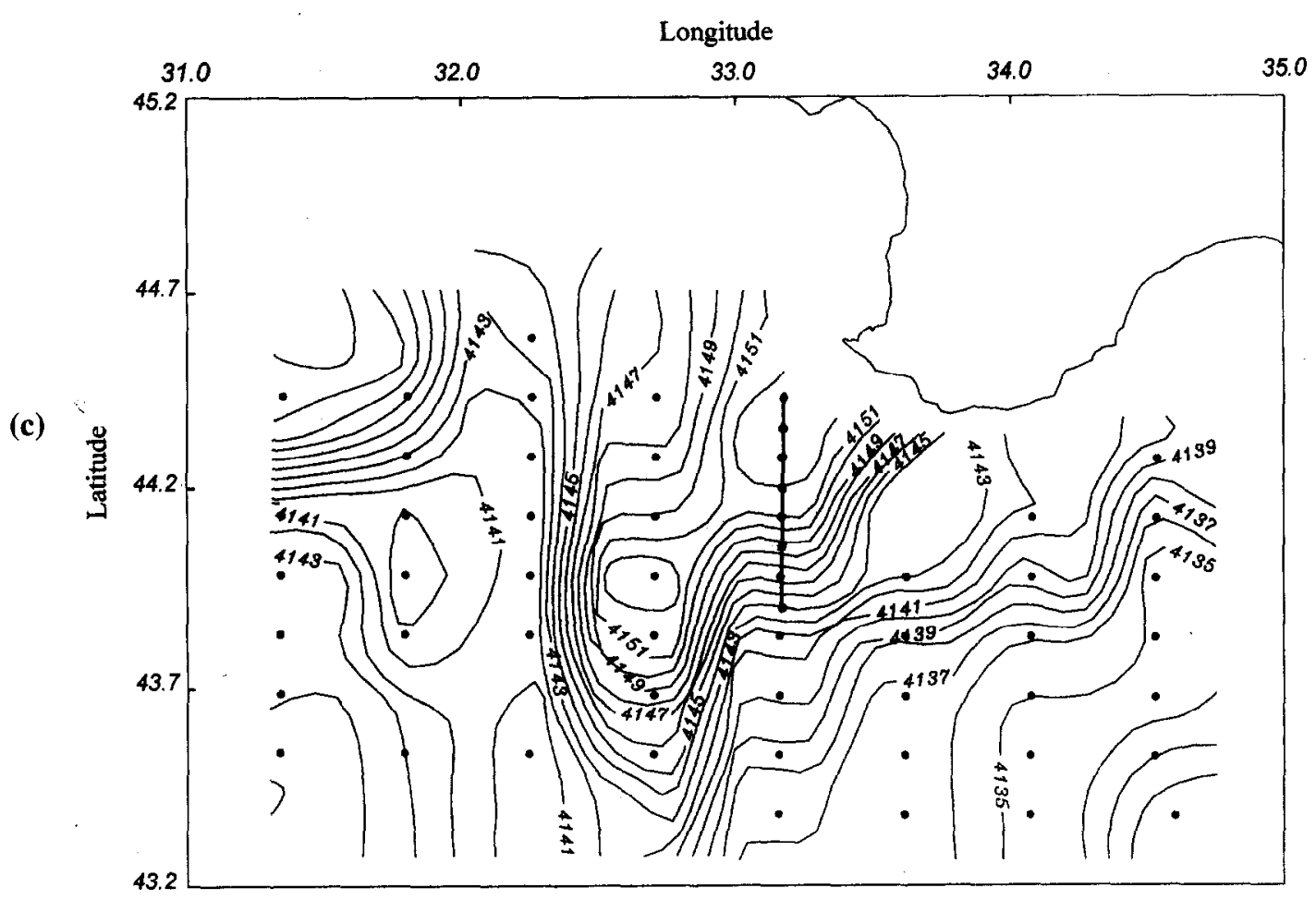

Figure 2. c- December 1994 (R.V. Prof. Kolesnikov, Cruise 32).

The solid line with dots indicates the cross-section along which vertical distributions of the sea water density and transparency were shown (see figures 3 and 4 ).

intermediate depths may result in the disappearance of these extremes towards the Black Sea coastal regions.

Hydrochemical data in the northern Black Sca (taken in December 1994) was obtained using water collection samples from bottles in conjunction with CTD "ISTOK-7". In total, these data represent over 6000 measurements of dissolved oxygen $\left(\mathrm{O}_{2}, \mathrm{n}=751\right)$, hydrogen sulfide $\left(\mathrm{H}_{2} \mathrm{~S}\right.$, $\mathrm{n}=492)$, phosphate $\left(P O_{4}, \mathrm{n}=971\right)$, nitrate $\left(N O_{3}, \mathrm{n}=649\right)$ and other biogen element concentrations. Locations of the hydrochemical and hydrological stations are represented by dots in figure $2 \mathrm{c}$.

The absolute and local extremes in the vertical distributions of various hydrochemical parameters are also thought to be formed through these dynamic processes. For example, graphs of the dissolved oxygen and hydrogen sulfide concentrations seem to be consistent with the proposed theoretical scheme of vertical water motion. The $\mathrm{O}_{2}$ and $\mathrm{H}_{2} \mathrm{~S}$ curves (see figure 5 ; based on composite data from Cruise 32 ) are plotted vs. density rather than depth. This scaling relative to density allows one to see more clearly the sharp vertical gradients across the pycnocline. The trends in these curves also confirm the similarity in vertical parameter distributions over much of the Black Sea. In the upper part of figure 5, one can see the mixed surface layer where the concentration of oxygen is more than $300 \mu \mathrm{M}$, an oxicline layer with sharp $\mathrm{O}_{2}$ variations; and a suboxic zone characterized by oxygen depletion $(<10 \mu \mathrm{M})$. The suboxic zone is also characterized by the onset of the sulfide regime, and $\mathrm{H}_{2} \mathrm{~S}$ concentration increases dramatically below this layer.

It can be seen, from the enlarged figure to the lower part of figure 5, that the minimums of oxygen and sulfide concentrations $(<10 \mu \mathrm{M})$ in the suboxic zone are strongly correlated with the lower boundary of the permanent pycnocline (15.9-16.2 $\sigma_{t}$ ) and the depths of the deep turbid layer. Supposing that the principal oxygen sources are located at the surface, that the major part of the sulfide is formed near the bottom of the Black Sea [2], and apply- 


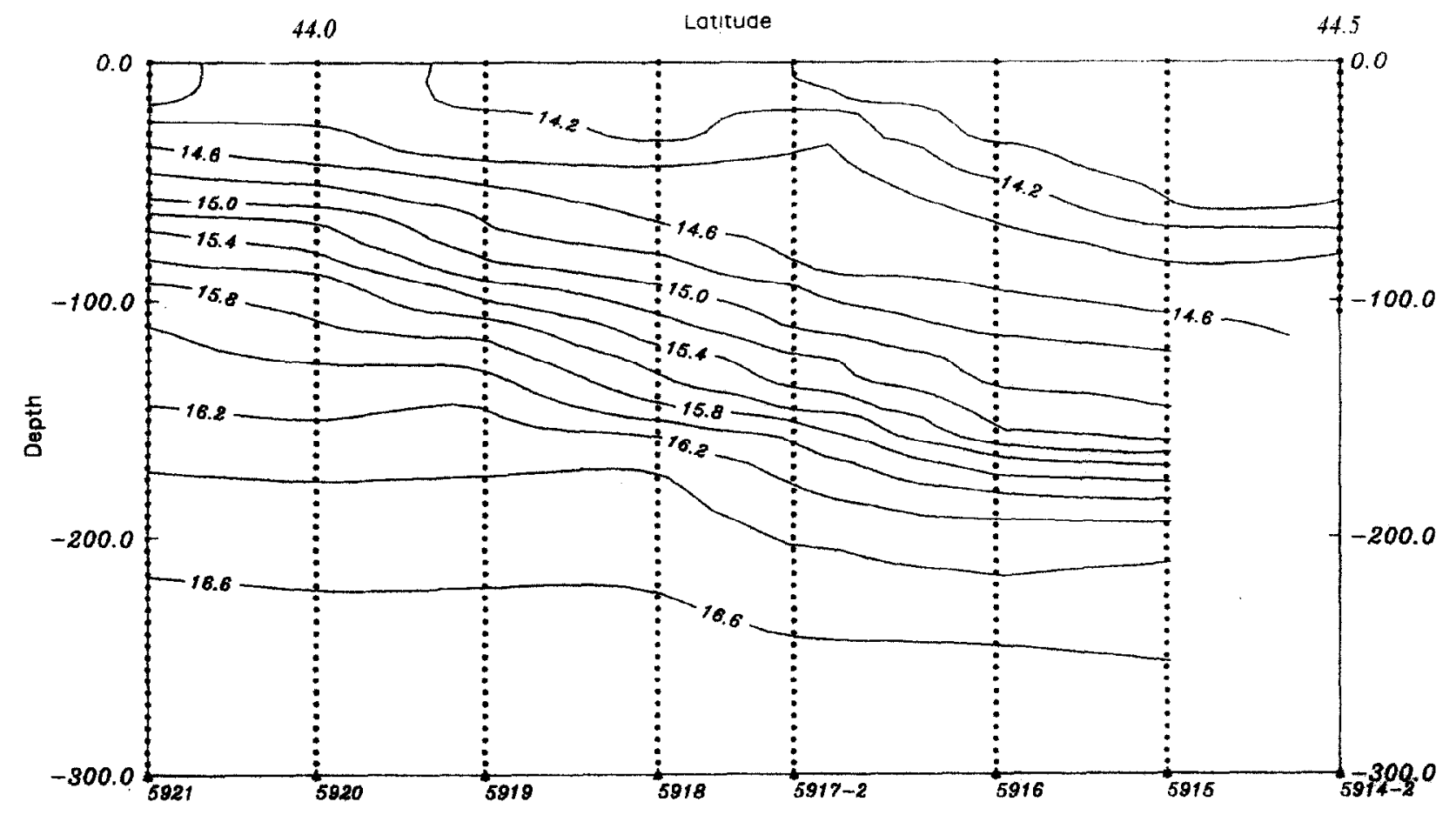

Figure 3. Vertical cross-section of the density field $\left(\sigma_{t}\right)$ along $33^{\circ} 15^{\prime} \mathrm{E}$ from data sampled during December 1994 (R.V. Prof. Kolesnikov, Cruise 32).

ing the theoretical scheme for sea water vertical circulation proposed above, it is not difficult to understand the observed vertical distributions of both $\mathrm{O}_{2}$ and $\mathrm{H}_{2} \mathrm{~S}$.

This behaviour is also shown by the vertical profiles of other hydrochemical parameters. Typical profiles of both phosphate $\left(\mathrm{PO}_{4}\right)$ and nitrate $\left(\mathrm{NO}_{3}\right)$ concentrations (sampled in December 1994; figure 6) show the existence of local extremums in biogenic element concentrations within the permanent pycnocline zone; a feature which may imply the convergence of vertical flows in the mid depths of the central basin.

Thus, the relationships observed between the vertical distributions of basic hydrological, hydrooptical and hydrochemical parameters can be explained by the character of the vertical motion in Black Sea waters. It is the restricted ventilation of the sea water in the permanent pycnocline depths that results in the previously noted extremes in hydrological, hydrochemical and hydrooptical parameters.

The most appropriate question to ask at this point, therefore, is whether the vertical circulation determined from observations is consistent with theoretical models of vertical water motion in the Black Sea.

\section{METHODS}

Two methods were applied for calculating $w(z)$ profiles. The first method was based on the continuity equation using:

$w(z)=-\int_{-z}^{0}\left[G_{v}(z)+G_{u}(z)\right] d z$

where $G_{v}=\frac{\partial v}{\partial y}$ and $G_{u}=\frac{\partial u}{\partial x}$

are the horizontal gradients of the meridional $(v)$ and zonal $(u)$ components of the velocity vector (axes ox, oy, $o z$ are directed eastwards, northwards and upwards respectively).

In order to evaluate $w(z)$, it follows (from eq. (1)) that it is necessary to determine horizontal gradients in velocity at the given horizons. Owing to the low gradients, their finite difference values are subject to significant distortions due to various noise factors, including instrumental errors and small-scale processes. It is therefore important to derive the most probable estimates for horizontal current gradients based on field meusurements acquired over an arbitrary observational grid $\left(x_{1} y_{1}, \ldots, x_{n} y_{n}\right)$. 


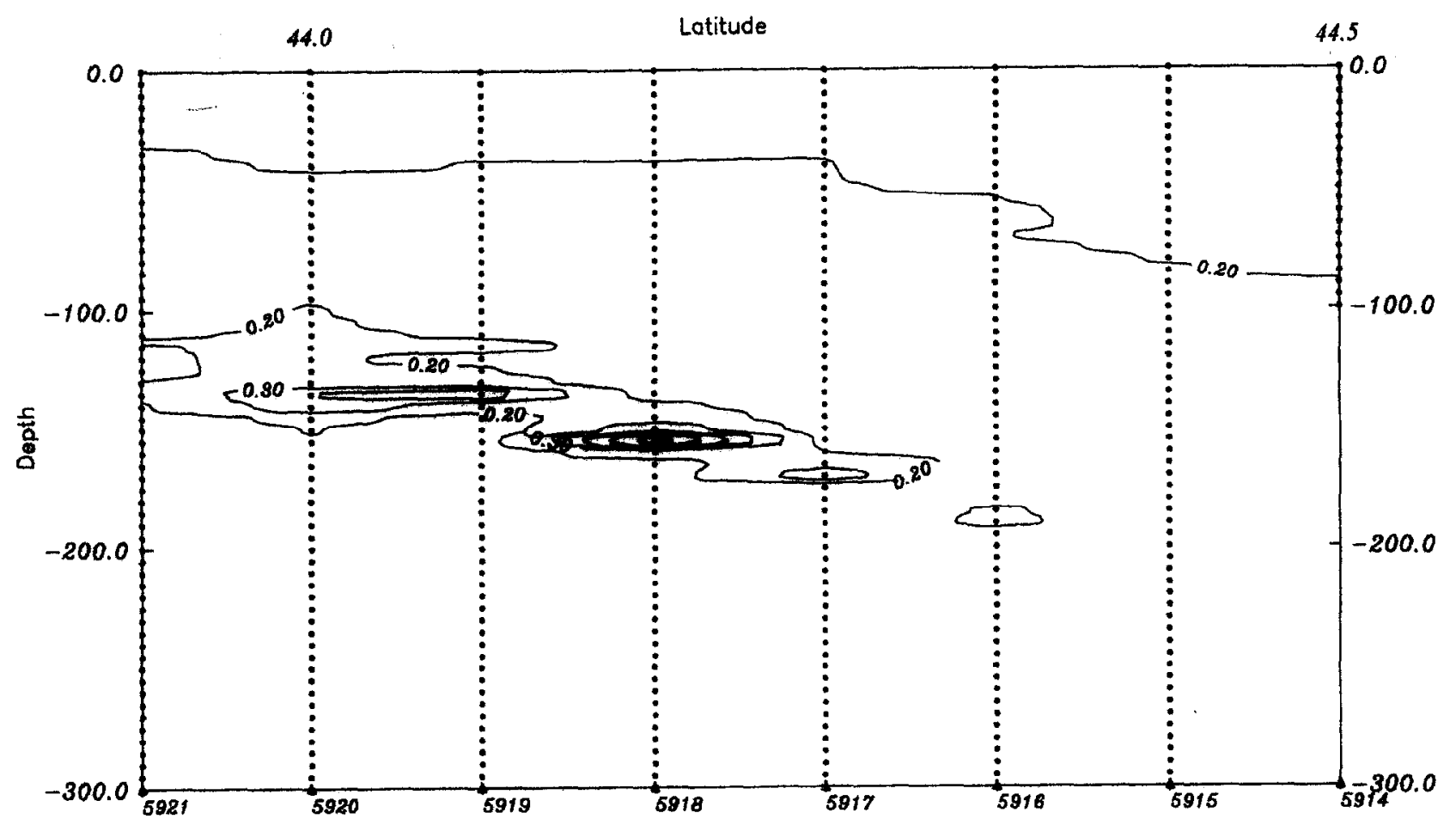

Figure 4. Vertical cross-section of the sea water transparency $(\varepsilon)$ in units $\mathrm{m}^{-1}$ along $33^{\circ} 15^{\prime} \mathrm{E}$ from data sampled in December 1994 (R.V. Prof. Kolesnikov, Cruise 32). The data was observed in the short-wave part of the spectrum (418 nm).

In terms of statistics, these horizontal gradients are derived from solutions of the maximum probability equations in accordance with a technique proposed by Kushnir et al. [22]. In particular,

$G_{v}=\frac{K_{v}}{S_{y}^{2}}, \quad G_{u}=\frac{K_{u}}{S_{x}^{2}}$

where

$K_{v}=\frac{1}{n-1}\left[\sum_{i=1}^{n}\left(v_{i}-\langle v\rangle\right)\left(y_{i}-\langle y\rangle\right)\right]$,
$K_{u}=\frac{1}{n-1}\left[\sum_{i=1}^{n}\left(u_{i}-\langle u\rangle\right)\left(x_{i}-\langle x\rangle\right)\right]$

are the sample correlations, and

$s_{y}^{2}=\frac{1}{n-1} \sum_{i=1}^{n}\left(y_{i}-\langle y\rangle\right)^{2}$,

$S_{x}^{2}=\frac{1}{n-1} \sum_{i=1}^{n}\left(x_{i}-\langle x\rangle\right)^{2}$ are the sample variances. The mean value of an observational sample $F_{i}$ is defined through

$\langle F\rangle=\frac{1}{n} \sum_{i=1}^{n} F_{i}$

where $n$ is the number of observational points [22].

For our case, the dispersion in $w$-error determinations at depth $z=i \Delta \mathrm{z}$ equals:

$$
\begin{aligned}
\sigma_{w}^{2}(z) & =0.25(\Delta z)^{2}\left[\sigma_{g v}^{2}(0)+\sigma_{g u}^{2}+\sigma_{g v}^{2}(i \Delta z)+\sigma_{g u}^{2}(i \Delta z)\right] \\
& +(\Delta z)^{2} \sum_{j=1}^{i-1}\left[\sigma_{g v}^{2}(j \Delta z)+\sigma_{g u}^{2}(j \Delta z)\right]
\end{aligned}
$$

where

$$
\begin{gathered}
\sigma_{g v}^{2}=\frac{\sigma_{v}^{2}+S_{v}^{2} S_{y}^{-2} \sigma_{l}^{2}}{(n-1) S_{y}^{2}}, \\
\sigma_{g u}^{2}=\frac{\sigma_{u}^{2}+S_{u}^{2} S_{x}^{-2} \sigma_{l}^{2}}{(n-1) S_{x}^{2}},
\end{gathered}
$$



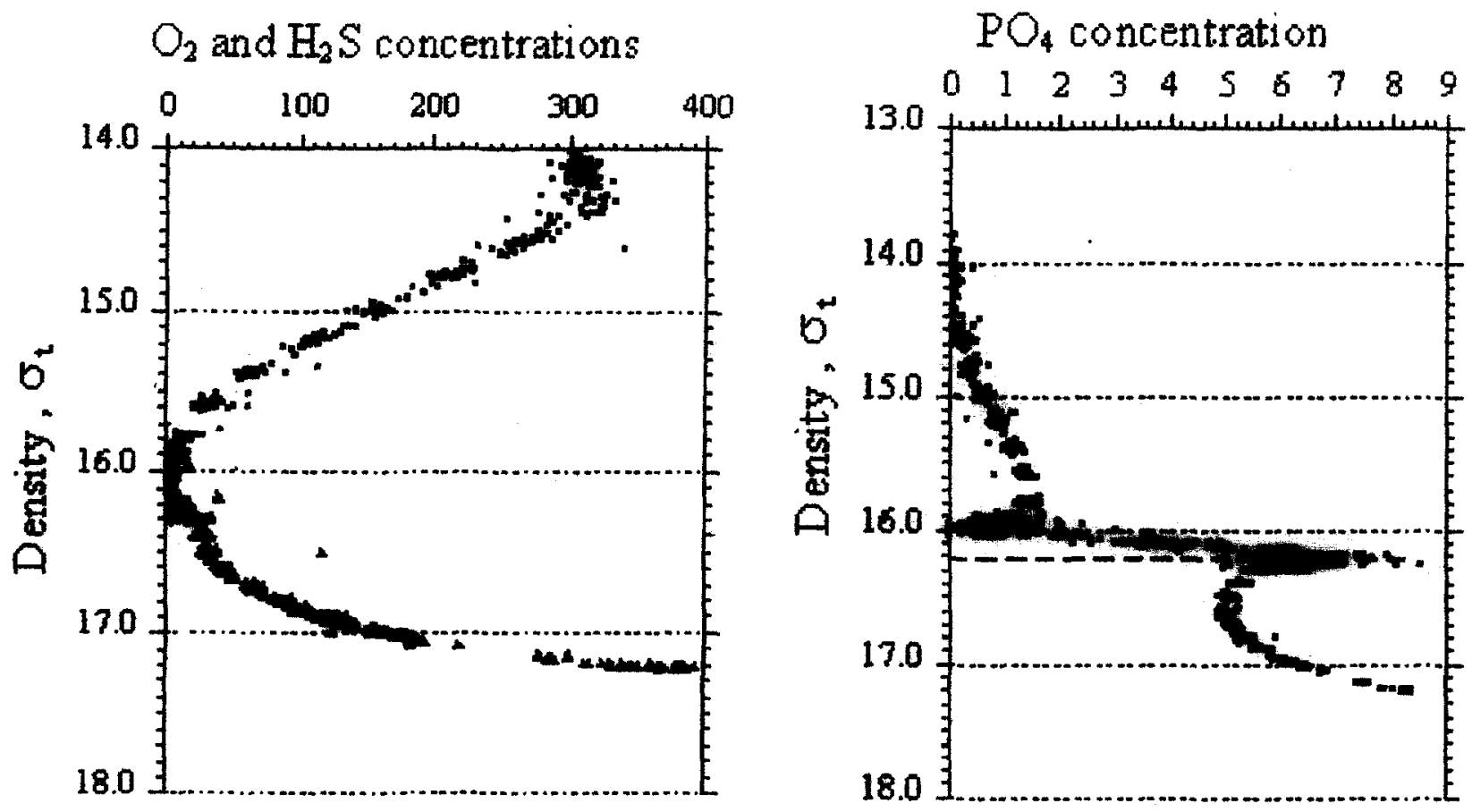

$\mathrm{O}_{2}$ and $\mathrm{H}_{2} \mathrm{~S}$ concentrations
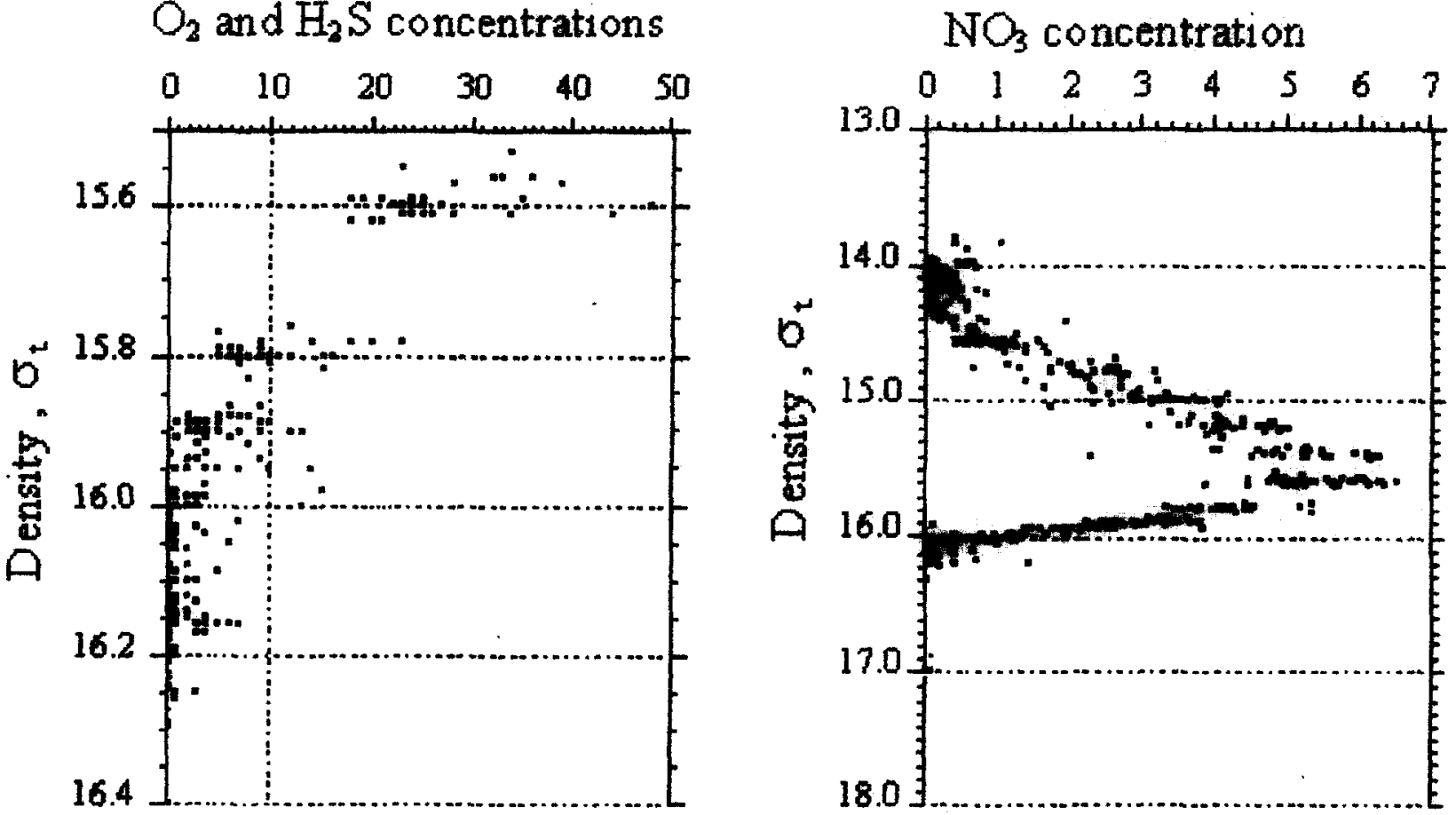

Figure 5. Dissolved oxygen $\left(\mathrm{O}_{2}\right)$ and hydrogen sulfide $\left(\mathrm{H}_{2} \mathrm{~S}\right)$ concentrations, all in units of $\mu \mathrm{M} \cdot \mathrm{kg}^{-1}$ and plotted relative to density $\left(\sigma_{t}\right)$. Data sampled in December 1994 (R.V. Prof. Kolesnikov,

Figure 6. Phosphate $\left(\mathrm{PO}_{4}\right)$ and nitrate $\left(\mathrm{NO}_{3}\right)$ concentrations, all in units of $\mu \mathrm{M} \cdot \mathrm{kg}^{-1}$ and plotted relative to density $\left(\sigma_{t}\right)$. Data sampled in December 1994 (R.V. Prof. Kolesnikov, Cruise 32). 
$S_{v}^{2}=\frac{1}{n-1} \sum_{i=1}^{n}\left(v_{i}-\langle v\rangle\right)^{2}$,

$S_{u}^{2}=\frac{1}{n-1} \sum_{i=1}^{n}\left(u_{i}-\langle u\rangle\right)^{2}$,

and $\sigma_{u}^{2}, \sigma_{v}^{2} \sigma_{l}^{2}$ are, respectively, the variances in the determination of current velocity profiles $u(z), v(z)$, and of the measured coordinate points $\left(x_{i}, y_{i}\right)$.

Another method makes use of the steady state density diffusivity equation, neglecting diffusivity terms. Given the geostrophic balance approximation for horizontal components of the velocity vector $[18,25]$ one then has:

$$
\begin{aligned}
w(z) & =J(\rho, p) \frac{1}{\rho_{0} f \frac{\partial \rho}{\partial z}} \\
& =\left(G_{p y} G_{d x}-G_{p x} G_{d y}\right) \frac{1}{\rho_{0} f G_{d z}}
\end{aligned}
$$

where $\left(G_{p x}, G_{p y}\right)$ are the pressure gradients, $\left(G_{d x}, G_{d y}\right.$, $G_{d z}$ ) are the density gradients, and the other symbols are conventional.

In a similar manner to that precribed above, the $p(x, y)$ distribution may be written in the general form:

$$
\begin{aligned}
& p=p_{0}+G_{p x} x+G_{p y} y+p^{\prime}, \\
& W\left(p^{\prime}\right)=\frac{1}{(2 \pi)^{1 / 2} \sigma_{p}} \exp \left[-\left(\frac{p^{\prime}}{2 \sigma_{p}}\right)^{2}\right],
\end{aligned}
$$

where $p^{\prime}$ is a pressure component caused by noise factors with Gaussian probability distribution, $W\left(p^{\prime}\right)$ is the density of the $p^{\prime}$ probability distribution, $p_{0}$ is the mean pressure value, and $\sigma_{p}^{2}$ is the noise component variance.

The conditional probability $P\left[p_{1}\left(x_{1} y_{1}\right), \quad p_{2}\left(x_{2} y_{2}\right), \ldots\right.$, $\left.p_{n}\left(x_{n} y_{n}\right) \mid G_{p x}, G_{p y}\right]$ corresponding to the maximum likelihood function is given by:

$$
\begin{aligned}
& P\left[p_{1}\left(x_{1} y_{1}\right), p_{2}\left(x_{2} y_{2}\right), \ldots, p_{n}\left(x_{n} y_{n}\right) \mid G_{p x} G_{p y}\right] \\
& \quad=\prod_{i=1}^{n} W\left(p_{i}, G_{p x}, G_{p y}\right)
\end{aligned}
$$

The maximal probability equations for the maximum $P$ value read:

$\frac{\partial \ln P}{\partial G_{p x}}=0, \quad \frac{\partial \ln P}{\partial G_{p y}}=0$
The solution of equation (11) has a form:

$$
\begin{aligned}
G_{p x} & =\frac{K_{x y} K_{p y}-S_{y}^{2} K_{p x}}{K_{x y}^{2}-S_{x}^{2} s_{y}^{2}}, \\
G_{p y} & =\frac{K_{x y} K_{p x}-s_{x}^{2} K_{p y}}{K_{x y}^{2}-s_{x}^{2} s_{y}^{2}},
\end{aligned}
$$

where

$$
\begin{aligned}
& K_{x y}=\sum_{i=1}^{n} x_{i} y_{i}, \quad K_{p x}=\sum_{i=1}^{n}\left(p_{i}-p_{0}\right) x_{i}, \\
& K_{p y}=\sum_{i=1}^{n}\left(p_{i}-p_{0}\right) y_{i} .
\end{aligned}
$$

The $K_{x y}$ value is determined by the configuration of density points. Taking into account the indefiniteness of the origin of the coordinate system $\left(x_{0}, y_{0}\right)$, let us consider the case when $x_{0}=\langle x\rangle, y_{0}=\langle y\rangle$, while

$$
\begin{aligned}
K_{x y} & =\sum_{i=1}^{n}\left(x_{i}-\langle x\rangle\right)\left(y_{i}-\langle y\rangle\right) \\
& =\frac{1}{n} \sum_{i=1}^{n} x_{i} y_{i}-\langle x\rangle\langle y\rangle
\end{aligned}
$$

It is easy to trace that $K_{x y}=0$ if the configuration of measured positions is symmetric relative to the $o x$ and $o y$ axes. In this case, formulas (12) are simplified to:

$G_{p x}=\frac{\sum_{i=1}^{n}\left(p_{i}-p_{0}\right)\left(x_{i}-\langle x\rangle\right)}{\sum_{i=1}^{n}\left(x_{i}-\langle x\rangle\right)^{2}}$,

$$
G_{p y}=\frac{\sum_{i=1}^{n}\left(p_{i}-p_{0}\right)\left(y_{i}-\langle y\rangle\right)}{\sum_{i=1}^{n}\left(y_{i}-\langle y\rangle\right)^{2}} .
$$

The station grid is generally represented by certain quasiregular structures, whilst the domains of the $w(z)$ calculations are rectangles. In such a case, equations (15) may be used to evaluate the vertical current velocity profiles. The technique for evaluating density gradients is similar. 
The measurements of density $\rho(z)$, pressure $p(z)$, and of the coordinate points possess errors, the variances of which will be designated as $\sigma_{d}^{2}, \sigma_{p}^{2}, \sigma_{l}^{2}$. These errors affect the accuracy with which the $w(z)$ profiles may be defined. In the case where equation (8) is applied, the variance in $w(z)$ is reduced to:

$\sigma_{w}^{2}=\frac{\sigma_{d y}^{2} \sigma_{p x}^{2}+\sigma_{d x}^{2} \sigma_{p y}^{2}}{\left(\rho_{0} f G_{d z}\right)^{2}}$

where $\sigma_{d y}^{2}, \sigma_{d x}^{2}, \sigma_{p y}^{2} \sigma_{p x}^{2}$, are, respectively, the variances in horizontal gradients of density and pressure along the $o y$ and $o x$ axes. These values equal:

$\sigma_{d y}^{2}=\frac{\sigma_{d}^{2}+S_{d}^{2} S_{y}^{-2} \sigma_{l}^{2}}{(n-1) S_{y}^{2}}, \quad \sigma_{d x}^{2}=\frac{\sigma_{d}^{2}+S_{d}^{2} s_{x}^{-2} \sigma_{l}^{2}}{(n-1) S_{x}^{2}}$,

$\sigma_{p y}^{2}=\frac{\sigma_{d}^{2}+S_{p}^{2} S_{y}^{-2} \sigma_{l}^{2}}{(n-1) S_{y}^{2}}, \quad \sigma_{p x}^{2}=\frac{\sigma_{d}^{2}+S_{p}^{2} S_{x}^{-2} \sigma_{l}^{2}}{(n-1) S_{x}^{2}}$,

where

$$
\begin{aligned}
& S_{d}^{2}=\frac{1}{n-1} \sum_{i=1}^{n}\left(\rho_{i}-\langle\rho\rangle\right)^{2}, \\
& S_{p}^{2}=\frac{1}{n-1} \sum_{i=1}^{n}\left(p_{i}-\langle p\rangle\right)^{2} .
\end{aligned}
$$

Thus, using two methods, and a set of horizontal current and density profiles it is possible to calculate optimal estimates fot the $w(z)$ profiles and related variances.

\section{RESULTS AND DISCUSSION}

An analysis of the vertical water motion characteristics was undertaken using observational data cited in section 2 . The $w(z)$ and $\sigma_{w}(z)$ profiles were calculated separately for the coastal zone and central basin, assuming opposing vertical circulation. The Black Sea Rim current was chosen as the boundary separating the central zone from the coastal region.

The profiles of vertical velocity $(w)$ and dispersion $\left(\sigma_{w}\right)$ based on current meter observations in the central (a) and coastal (b) regions of the NW Black Sea derived in August 1992 are presented in figure 7 . The main peculiarity of the $w(z)$ vertical profiles is their two-layered structure, with zero velocities occurring at intermediate depths. In the open basin, a downwelling is observed in the upper sea layer, and an upwelling is noted below $300 \mathrm{~m}$. By contrast, the water upwelling in the coastal zone originates in an upper sea layer, and the downwelling flows derive from layers deeper than $250 \mathrm{~m}$. These trends are consistent with the scheme of vertical circulation proposed for the Black Sea.

The vertical current velocity profiles are indicated in figure 8, based on data from the autumn 1993 survey of the central area (a) and outside of it (b). The main characteristic of the calculated vertical profiles is their two-layered structure, a feature which was also found from the results of the R.V. Y. Gakkel expedition (see above). In the upper layer of the central basin the vertical current propagates downward, whilst below the pycnocline (>350 m) it propagates upward. In coastal areas, the picture is roughly the reverse.

Similar calculations for vertical current velocities, and standard deviations of those estimates were computed for data from the R.V. Prof. Kolesnikov expedition (December 1994) which covered several polygons in the northern part of the Black Sea. The general peculiarities of the $w(z)$ structure in the central zone and outside it turn out to be similar to those of the R.V. Trepang and R.V. Y. Gakkel surveys. As well as yielding the $w(z)$ profiles, illustrated in figures 7 and 8 , the calculations showed the presence of a two-layered structure, with the zero values of vertical velocity at the 100-200 m horizons (figure 9). This layer corresponds well to the position of the hydrological, hydrooptical and hydrochemical extremes discussed above, and presented in figures 3-6.

So, the calculated $w(z)$ profiles for all three surveys correspond qualitatively to the theoretical scheme of the sea water vertical circulation in the Black Sea. It therefore makes sense to undertake a quantitative comparison of the present observational results with theoretical estimates.

From Bulgakov [7] and Bulgakov et al. [8], the characteristic scale of the buoyancy flux induced vertical velocity is

$W=\frac{\delta \rho \cdot g \cdot H^{2}}{\rho \cdot f \cdot L^{2}}$

Taking $g=9.8 \mathrm{~m} \cdot \mathrm{s}^{-2}, f=10^{-4} \mathrm{~s}^{-1}$, a horizontal density difference $\delta \rho / \rho=10^{-2}$, and horizontal and vertical basin scales $L=3 \times 10^{5} \mathrm{~m}$ and $H=10^{3} \mathrm{~m}$ then gives $W=10^{-2} \mathrm{~m} \cdot \mathrm{s}^{-1}$. Because the maximum values of the dimensionless vertical velocities were about $w=4 \times 10^{-3}$ for the chosen range of model parameters, it follows that 


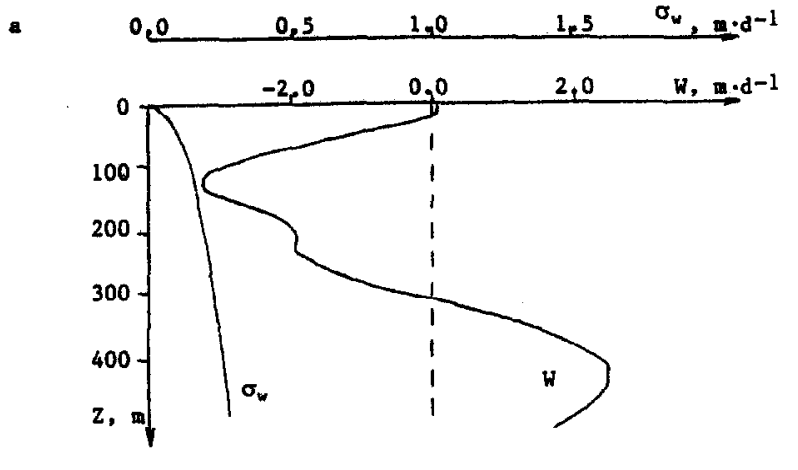

b

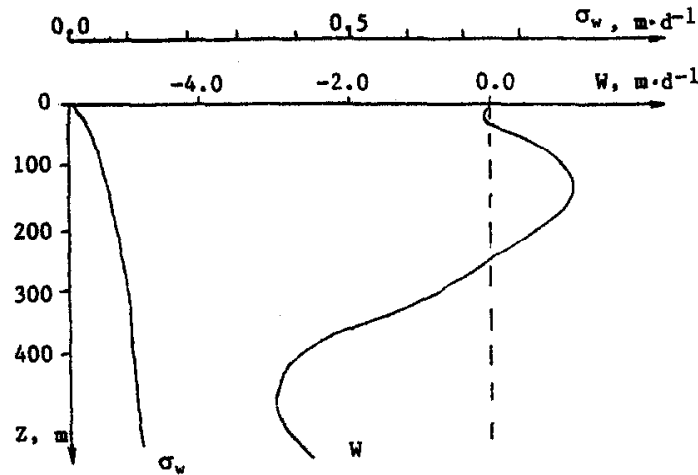

Figure 7. Profiles of vertical velocity $(w)$ and corresponding dispersion $\left(\sigma_{w}\right)$ based on current meter observations in the open (a) and coastal (b) regions of the northwest Black Sea during August 1992 (R.V. Y. Gakkel).

the theoretical estimation is $w=3.45 \mathrm{~m} \cdot \mathrm{d}^{-1}$; a value which is close to what is observed. As is obvious from figures $7-9$, the absolute values of vertical velocity may approach $3-4 \mathrm{~m} \cdot \mathrm{d}^{-1}$.

These maximum $w$-values are also similar to the estimates for tropical and equatorial ocean zones by Belevich [1], Kozlov [20], Latun [24], Hlystov and Dzhiganshin [19], Chekotillo [13], Hall [18] and Poulain [33]. On the other hand, such values exceed the estimates for the polar front [25] by a factor of three, and are less than those for the Gulf Stream [26] by a factor of ten.

Altogether, eleven $w(z)$ profiles were obtained using current meter data, and the boundary between opposing vertical motions covered a range of depths 40 to $310 \mathrm{~m}$. The average depth of this boundary (149 $\mathrm{m} \pm 70 \mathrm{~m})$ corresponds to the lower boundary of the permanent pycnocline for the central part of the northern Black Sea. Relatively large root-mean-square deviations in boundary depth may arise from two factors. First, there is the possible influence of natural variability in pycnocline structure due to

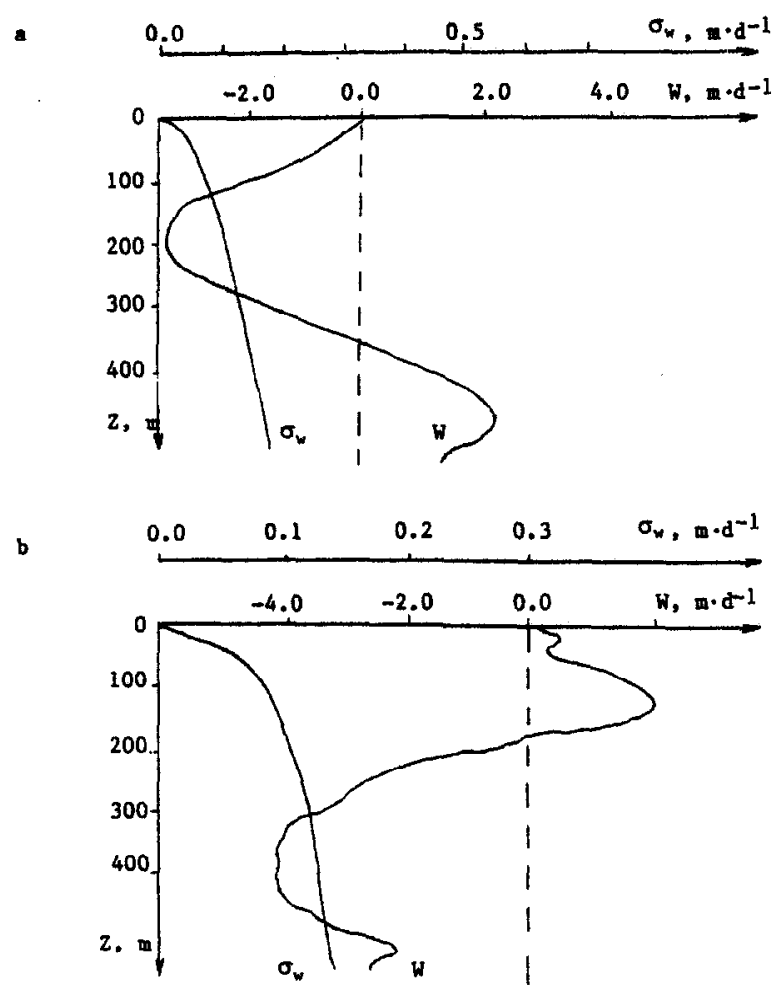

Figure 8. Profiles of vertical velocity ( $w$ ) and corresponding dispersion $\left(\sigma_{w}\right)$ based on current meter observations in the open (a) and coastal (b) regions of the NW Black Sea during October-November 1993 (R.V. Trepang, Cruise 15).

Rim current meandering, and the formation of eddies with opposite rotation. According to the present measurements, for example, the depth of the maximum vertical density gradient in the main pycnocline may change by more than $100 \mathrm{~m}$, depending on the eddy rotation sign of the location where measurements are carried out. The second influence may be related to the statistical variation in vertical current velocity estimates; the profiles show that the corresponding root-mean-square deviations are commensurable with the value of $w$.

Independent vertical current velocity profiles have been calculated using the second method, and density data deriving from CTD observations on the R.V. Prof. Kolesnikov (Cruise 32; December 1994). Altogether, twelve vertical current velocity profiles were obtained, and figure 10 shows corresponding $w$-profiles for the open (a) and coastal (b) zones. These profiles were determined for two rectangles with the centres at $\left(43^{\circ} 35^{\prime} \mathrm{N}\right.$; $\left.34^{\circ} 00^{\prime} \mathrm{E}\right)$ and $\left(44^{\circ} 25^{\prime} \mathrm{N} ; 32^{\circ} 00^{\prime} \mathrm{E}\right)$. Their main characteristic is a two-layered structure, with zero velocity 


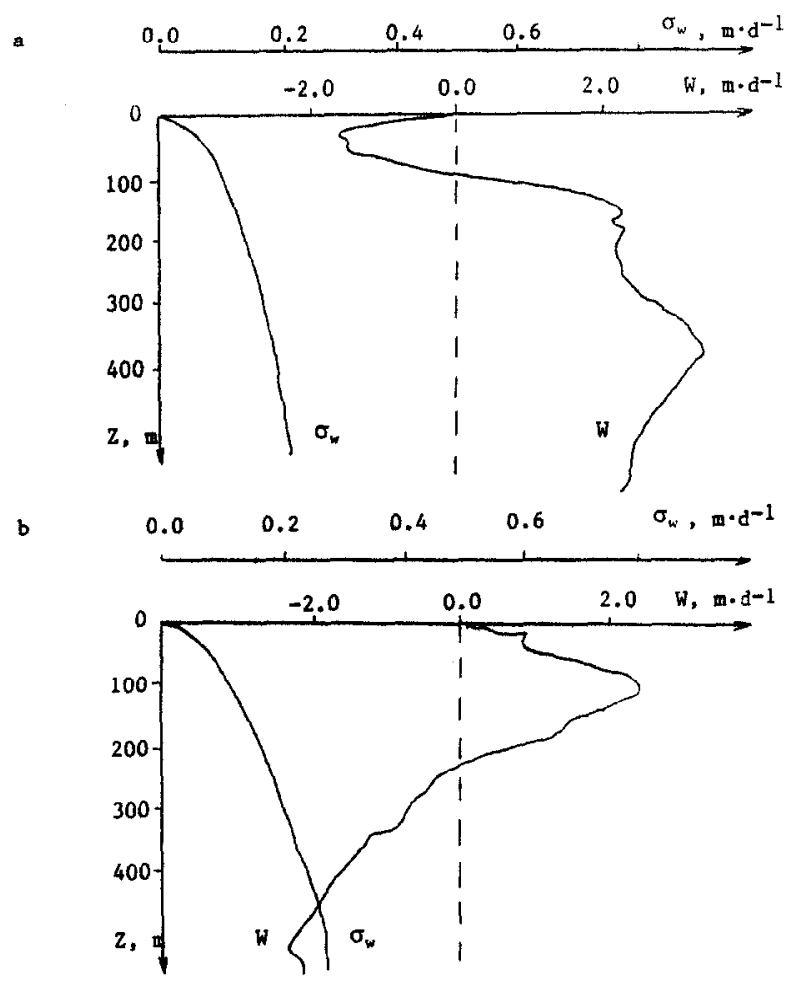

Figure 9. Profiles of vertical velocity ( $w$ ) and corresponding dispersion $\left(\sigma_{w}\right)$ based on current meter observations in the open (a) and coastal (b) regions of the NW Black Sea during December 1994 (R.V. Prof. Kolesnikov, Cruise 32).

occuring in the permanent pycnocline depths (100$150 \mathrm{~m}$ ), and vertical $w$-profiles of opposite sign in the upper and deeper layers of the coastal and central zones. The maximum value of vertical velocity determined from density data is $0.5-1.0 \mathrm{~m} \cdot \mathrm{d}^{-1}$; somewhat less than analogous estimates based on the first method. Nevertheless, the results agree at the qualitative level.

The dispersion in $w(z)$ resulting from density errors was evaluated at depths of 80 and $120 \mathrm{~m}$, where maximal vertical density gradients were observed, whence we found $\sigma_{w}$ standard deviations of respective 0.095 and $0.105 \cdot \mathrm{m} \mathrm{d}^{-1}$. The corresponding RMS deviations are $\pm 0.19 \cdot \mathrm{m} \mathrm{d}^{-1}$ and $\pm 0.21 \mathrm{~m} \cdot \mathrm{d}^{-1}$ to a $95 \%$ level of probability.

Evaluation of vertical current velocity profiles was carried out recently [23] for the northeastem Black Sea using density observations taken in the summer of 1991. A two-layered $w$-structure, with zero velocity values at the permanent pycnocline was found there also. It could
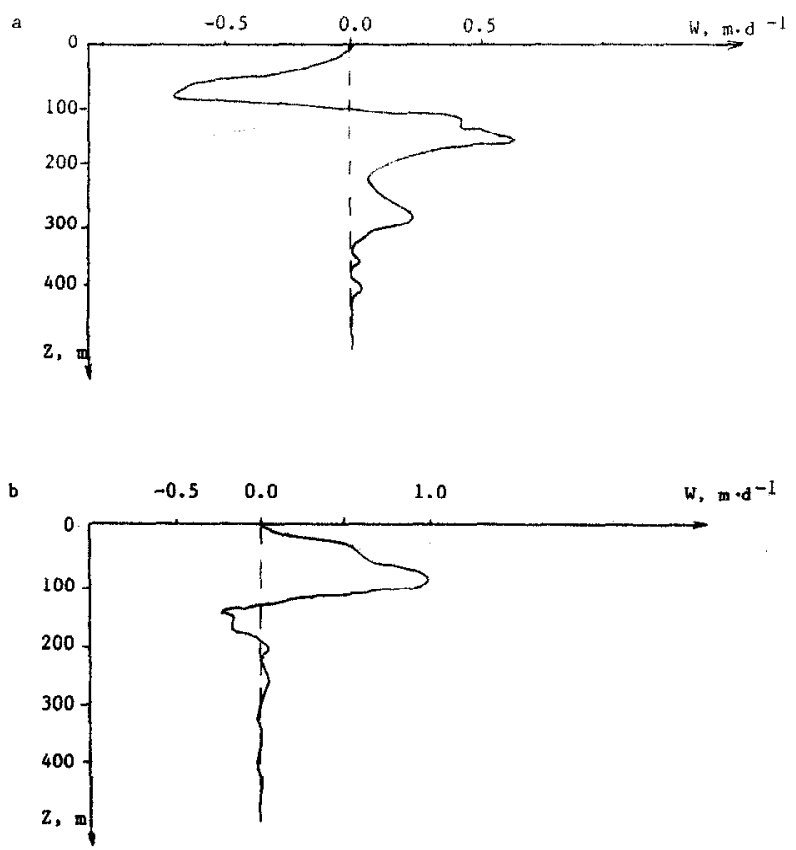

Figure 10. Profiles of vertical velocity ( $w$ ) based on density observations in the open (a) and coastal (b) regions of the NW Black Sea during December 1994 (R.V. Prof. Kolesnikov, Cruise 32). The profiles were calculated for two rectangles centred at $\left(43^{\circ} 35^{\prime} \mathrm{N}\right.$; $\left.34^{\circ} 00^{\prime} \mathrm{E}\right)$ and $\left(44^{\circ} 25^{\prime} \mathrm{N} ; 32^{\circ} 00^{\prime} \mathrm{E}\right)$.

testify to the assumed character of the sea water vertical motion in various Black Sea regions.

Thus, vertical current velocity estimates based on two methods have demonstrated that caleulated vertical current velocity profiles have a two-layered structure, with zero velocity values in the permanent pycnocline (15.916.2 $\sigma_{1}$ ). This agrees with the proposed scheme of vertical sea water motion, and allows us to explain the existence of extremes in hydrochemical and hydrooptical properties within the Black Sea.

The agreement between vertical water motion derived from theoretical analysis, and trends derived from observations, emphasises the possible importance of buoyancy fluxes as a driving force in the Black Sea. It seems that the human impact on the Black Sea driving forces (through reduction in fresh water input) may seriously affect dynamic processes within the Black Sea basin, and lead to various negative consequences, such as the variation of the oxic-anoxic interface position; a reduction in biological resources; and general deterioration of sea water quality. 


\section{CONCLUSIONS}

An investigation of vertical circulation in the Black Sea has been carried out using processing of the current meter measurements and density data sampled during 19921994. The results demonstrate the existence of two different types of $w(z)$ profiles characteristic of the coastal and central Black Sea, as well as a two-layered system of the vertical water motion with zero velocities occurring in the permanent pycnocline. Such vertical circulation is similar to the theoretical scheme of the buoyancy flux induced dynamics $[8,10]$.

The apparent existence of converging vertical flows at intermediate depths of the central Black Sea provides an explanation of pycnocline formation, as well as the observed extremes in hydrochemical and hydrooptical parameters, and such Black Sea phenomena as the deep turbid layer, suboxic zone, etc.
We would stress once again the importance of further studies of $w$-structures using various theoretical schemes, and procedures for in situ data processing in order to obtain a better understanding of the relationships observed between hydrological, hydrochemical and hydrooptical parameters in the Black Sea.

\section{Acknowledgements}

The authors are very grateful to all their colleagues from Marine Hydrophysical Institute of the Ukrainian National Academy of Sciences who participated in these cruises, as well as to Dr. Mankovsky V.I. and $\Lambda . S$. Romanov for their analysis and interpretation of the hydrooptical and hydrochemical data, and Dr. Morozov A.N. and L.N. Repetin for their organisation of hydrophysical studies in the Black Sea from 1992 to 1994.

\section{REFERENCES}

[1] Belevich R.R., The sea water vertical circulation in northern tropical and equatorial zones of the Pacific Ocean, Trudy GOIN, 90 (1967) 3-61 (in Russian).

[2] Bezborodov A.A., Eremeev V.N., The Black Sea, The zone of interaction of oxic and anoxic waters, Sevastopol, ECOCIHydrophysica Pub. (1993) 298 p. (in Russian, abstract in English).

[3] Blatov A.S., Bulgakov N.P., Ivanov V.A., Kosarev A.N., Tuzhilkin V.S., Variability of hydrophysical fields of the Black Sea, Leningrad, Gidrometeoizdat (1984) 240 p. (in Russian).

[4] Brewer P., Hydrographic and chemical data from the Black Sea, Woods Hole Oceanographic Institution Technical Report (1971) Reference No. 71-65.

[5] Buesseler K.O., Livingston H.D., Ivanov L., Romanov A., Stability of the oxic-anoxic interface in the Black Sea, Deep-Sea Res. I, 41 (2) (1994) 283-296.

[6] Bulgakov S.N., Korotaev G.K., The possible mechanism of stationary circulation of the Black Sea waters, Complex studies of the Black Sea, Sevastopol, Mar. Hydrophys. Inst. (1984) 32-40 (in Russian).

[7] Bulgakov S.N., Black Sea large-scale circulation and water stratification formation, Buoyancy flux impact, Nation. Acad. Sci. of Ukraine, Mar. Hydrophys. Inst., Sevastopol (1996) 243 p. (in Russian, abstract in English).

[8] Bulgakov S.N., Korotaev G.K., Whitehead J.A., The role of buoyancy fluxes in the formation of a large-scale circulation and stratification of sea water, Part 1: The theory, Izvestiya Atmospheric and Oceanic Physics, Engl. Transl. 32 (4) (1996a) 506-513.
[9] Bulgakov S.N., Korotaev G.K., Whitehead J.A., The role of buoyancy fluxes in the formation of a large-scale circulation and stratification of sea water, Part 2: Laboratory experiments, Izvestiya - Atmospheric and Oceanic Physics, Engl. Transl. 32 (4) (1996b) 514-520.

[10] Bulgakov S.N., Korotaev G.K., Whitehead J.A., A linear model of buoyancy driven circulation in the Black Sea, DeepSea Res. Special Volume on the Black Sea: Oceanographic variability (1998) in press.

[11] Bulgakov S.N., Kushnir V.M., Peculiarities of the current field in the NW Black Sea, Mar. Hydrophys. J. 5 (1996a) 66-80 (in Russian, abstract in English).

[12] Bulgakov S.N., Kushnir V.M., Vertical structure of the current field in the Northern Black Sea, Oceanologica Acta, 19 (5) (1996b) 513-522.

[13] Chekotillo K.A., The intensity of the ocean waters vertical transfer, Reports of Russ. Ac. Sci. 153 (3) (1963) 585-587 (in Russian, abstract in English).

[14] Codispoti L.A., Friederich G.E., Murray J.W., Sakamoto C., Chemical variability in the Black Sea: implications of data obtained with a continuous vertical profiling system that penetrated the oxic/anoxic interface, Deep-Sea Res. 38 (S2A) (1991) S691-S710.

[15] Filippov D.M., Circulation and water structure of the Black Sea, Moscow, Nauka (1968) 136 p. (in Russian, abstract in English).

[16] Fonslus S.H., Model of the water balance in the Black Sea, in: The Black Sea - geology, chemistry and biology, Tulsa, Oklahoma (1974) 575-590. 
[17] Gupta R.S., Oceanography of the Black Sea: Inorganic nitrogen compounds, Deep-Sea Res. 18 (1971) 457-475.

[18] Hall M.M., Horizontal and vertical structure of the Gulf Stream velocity field at $68^{\circ} \mathrm{W}$. J. Phys. Oceanogr. 16 (1986) 1814-1828.

[19] Hlystov N.Z., Dzhiganshin G.F., The vertical circulation of the Tropical Atlantic waters, Mar. Hydrophys. Res. 3 (66) (1974) 85-101 (in Russian).

[20] Kozlov V.F., On the water upwelling at the equator region, Oceanology 4 (1) (1964) 43-50 (in Russian, abstract in English).

[21] Kushnir V.M., Probe of vertical profiling of currents and hydrological elements, Oceanology, Fngl. Transl. 34 (2) (1994) 275-277.

[22] Kushnir V.M., Bulgakov S.N., Danilova I.A., Lebedeva T.P., Optimal statistic evaluations of the vertical current velocity in the north-western Black Sea, Phys. Oceanogr. 8 (3) (1997) 205- 215.

[23] Kushnir V.M., Yunev O.A., Fenenko Z.Z., Influence of the synoptic vertical currents on the chlorophyll $a$ distribution in the Black Sea, Oceanology, 39 (2) (1999) 202-211.

[24] Latun V.M., The vertical movements at the zero velocity dynamic surface in Atlantic ocean, Oceanology 3 (2) (1963) 206212 (in Russian, abstract in English).

[25] Leach $\mathrm{H}$., The diagnosis of synoptic-scale vertical motion in the seasonal thermocline, Deep-Sea Res. 34 (1987) 20052017.

[26] Lindstorm S.S., Watts D.R., Vertical motion in the Gulf Stream near $68^{\circ} \mathrm{W}, \mathrm{J}$. Phys. Oceanogr. 24 (1994) 2321-2333.

[27] Maderich V.S., Efroimson V.O., Simple model of the sea with strait, Oceanology 26 (3) (1986) 402-408 (in Russian, abstract in English).

[28] Mankovsky V.I., Optical structure of the Black Sea and conformity of its formation, Hydrophysical and hydrochemical studies of the Black Sea, Mar. Hydrophys. Inst., Sevastopol (1992) 7-27 (in Russian).

[29] Marchuk G.I., Kordzadze A.A., Skiba Yu. N., Calculations of the principal hydrological fields of the Black Sea, Izvestiya -
Atmospheric and Oceanic Physics, 11 (4) (1975) 379-393 (in Russian, abstract in English).

[30] Murray J.M., Top Z., Ozsoy E., Hydrographic properties and ventilation of the Black Sea, Deep-Sea Res. 38 (S2A) (1991) S663-S690.

[31] Neuymin G.G., The stable turbid deep-water layer in the Black Sea, Mar. Hydrophys. Res. 1 (47) (1970) 178-191 (in Russian).

[32] Ozsoy E., Top Z., White G., Murray J.W., Double diffusive intrusion, mixing and deep-sea convection processes in the Black Sea, in: Izdar E., Murray J.M., (Eds.), Black Sea oceanography, Kluwer Academic Publishers, The Netherlands (1991) 1742 .

[33] Poulain P.M., Estimates of horizontal divergence and vertical velocity in the Equatorial Pacific, J. Phys. Oceanogr. 23 (1993) 601-607.

[34] Sarkisyan A., Demin Y., Trukhchev D., To the calculation of the vertical velocity in models of sea currents, Izvestiya Atmospheric and Oceanic Physics, Engl. Transl. 19 (7) (1983) 730-740.

[35] Saydam C., Tugrul S., Basturk O., Oguz T., Identification of the oxic/anoxic interface by isopycnal surfaces in the Black Sea, Deep-Sea Res. I, 40 (1993) 1405-1412.

[36] Shkudova G.Y., Dzhioev T.Z., Numerical experiment on the calculation of the Black Sea vertical water motion, Meteorology and Hydrology 11 (1975) 66-71 (in Russian, abstract in English).

[37] Simonov A.I., Altman E.N., Hydrometeorology and hydrochemistry of the USSR seas, Vol. 4: The Black Sea, Issue 1: Hydrometeorological conditions, St. Petersburg, Hydrometeoizdat (1991) 429 p. (in Russian).

[38] Stanev E.V., Numerical study on the Black Sea circulation, Mitteilungen des Institut für Meereskunde der Universität Hamburg. 28 (1988) $232 \mathrm{p}$.

[39] Vodyanitsky V.A., General water exchange and history of the Black Sea salinity formation, Trudy SBS, 6 (1948) 386-432 (in Russian). 